\title{
Speech Act of Thanking: A Contrastive Analysis among Iranian EFL learners in terms of gender and level of proficiency
}

\author{
Mina Azima ${ }^{1}$, Akbar Hesabi $^{2}$ \\ ${ }^{1}$ Najafabad Branch, Islamic Azad University, Najafabad, Iran \\ ${ }^{2}$ University of Isfahan, Isfahan, Iran \\ E-mail address: mina_azima@yahoo.com; a.hesabi11@yahoo.com
}

\section{Keywords: Speech act, Thanking, Gender, Level of proficiency}

\begin{abstract}
The speech act of thanking is one of the fairly neglected areas of research in the Iranian context. The present study seeks to investigate the ways in which this social act is expressed by young male and female EFL learners. To collect the data for this study sixty participants (30 males, 30 females) were selected randomly from among the population of BA and MA students of Najafabad university and students learning English in a language institutes located in Najafabad. The major focus of this study was the role that gender and individuals' level of proficiency might play in the application of thanking strategies. Students were asked to complete a discourse completion test (DCT). They were supposed to read thirteen natural situations, and react to them via expressing gratitude. In order to analyze the utterances of thanking, Cheng's coding scheme was employed. Students' responses were further classified according to the gender and level of proficiency. The results revealed that the females were more cautious in selecting strategies of gratitude. Individuals' level of proficiency was also found to play an important role in the process of strategy selection.
\end{abstract}

\section{INTRODUCTION}

Producing the appropriate language in different situations is essential for successful communication; In order to achieve this goal, one should acquire pragmatic competence alongside the grammatical one.

Mey (1993) has mentioned that pragmatics is the science of language which is practiced by people in their real lives; he also asserted that speech acts are the most fundamental part of pragmatics. Cutting (2002) defined speech acts as actions which are performed by saying something and stated that being able to use the appropriate speech acts can be defined as having the knowledge to communicate with others. One of the most commonly used speech acts in everyday interactions is the speech act of gratitude which has been defined as a kind of illocutionary act that a speaker performs based on the act of the hearer in the past (Eisenstein \& Bodman, 1986, p. 167).

In order to express the gratitude one can use words of thanks, praise or appreciation (Van Ek, 1977, as cited in Eisenstein \& Bodman, 1986). The word "thank you" expresses an emotional attitude and there are several phrases which may be used by speakers in thanking. Since thanking has a societal role, learners should acquire rules for expressing gratitude in the target language. From the fact that thanking is implemented by means of standardized routines, learners not only should know the semantic formulas needed in thanking situations, but also have to interpret the appropriate time to apply these formulas (Blum-Kulka \& Olshtain, 1984).

Moreover, the daily language and use of speech acts may be affected by factors among which gender is one (Wardhaugh, 2002); so conducting a study which focuses on the differences that exist between males/females in expressing the speech act of gratitude is necessary. 


\section{LITERATURE REVIEW}

While many studies have been performed to examine the ways in which compliments are used and responded to (Pomerantz, 1978; Wolfson \& Manes, 1980; Holmes, 1986) little attention has been paid to the expressions of gratitude.

The most important point about the expressions of gratitude is that although people learn to express them at an early age, and the native speakers of all languages express them in the most appropriate way, previous research studies revealed that, even advanced language learners have difficulty adequately expressing gratitude (Eisenstein \& Bodman, 1986, 1993; Hinkel, 1994).

Children are constantly instructed by parents or caregivers that thanking is a matter of politeness, however, like many politeness conventions, there appears to be a large degree of cross-cultural variation in the use and realization of thanking expressions.

Based on the societal function of thanking which is brought out in the early stages of life, Eisenstein and Bodman (1968) mentioned that if expressions of gratitude are used appropriately, they can provide feelings of warmth and solidarity among interlocutors, they also stated the point that Expressions of gratitude can be grouped as simple, phatic utterance to lengthy communicative events developed by both giver and recipient of a gift, favor, reward or service.

Thus, saying thank you, may pose problems for a second language learner, who needs to know when and how to thank in the target culture (Bodman \& Eisenstein, 1988; Eisenstein \&Bodman, 1986, 1993). The problem is typically debated in terms of when and how thanking is an appropriate response to the social situation. As Coulmas (1981, P.75) puts it: The social relation of the participants and the inherent properties of the object of gratitude work together to determine the degree of gratefulness that should be expressed in a given situation. Differences in this respect are obviously subject to cultural variation.

Therefore, according to the rules of politeness in a second language community, simply knowing how to say thank you in a second language does not mean one is capable of recognizing the situations when thanking is appropriate or the extent to which thanks should be given.

Apte's (1974) study is one of the earliest investigations of expressions of thanking. He compared giving thanks in Marathi and Hindi to expressing gratitude in American English and found that " the usage of gratitude expressions in American culture is much more extensive than in South Asian communities" (p. 84). While in the American English giving thanks for favors, gifts or services is considered appropriate and expected, for Marathi and Hindi expressing gratitude to family members or close friends for favors violates the feeling of closeness, as it is the duty of family members and close friends to help each other.

In another influential study Eisenstein and Bodman (1986) compared the use of expressions of gratitude by groups of participants with different language backgrounds and American English native speakers. They found that while certain language groups performed better than others, e.g. the results of the Russian speakers were better than those of the Japanese speakers, "the problems exhibited by [their] non-native speakers were extensive and severe" (1986, p. 173).

Cheng (2005) also studied the similarities and differences between native speakers of Chinese and native speakers of English in expression of gratitude by examining the length of their utterances and their use of strategies through a discourse completion task questionnaire. He also examined the sign of pragmatic development and the influence of their first language on producing the expressions of gratitude in the speech act behavior among Chinese learners of English. The results showed that Chinese and English native speakers had different choices of thanking strategies. The findings of his study revealed that the difference in length of speech and use of strategies were affected by contextual variables, social status, and familiarity.

Like the previously mentioned studies Ohashi's (2000) $\mathrm{PhD}$ thesis revealed another interesting fact about the expressions of gratitude, in his thesis he clearly states that Japanese thanking is not the expression of gratitude or appreciation, but a symbolic repayment of debt with which the beneficiary redresses the debt-credit imbalance. This result is in line with Miyake (1994), Nakata (1989), Nakai and Watanabe (2000). Nakamura (2005) comparing English and Japanese thanks noted that while American English native speakers tended to use more compliments when 
expressing gratitude than Japanese native speakers, Japanese native speakers employed more apologetic expressions.

Regarding Persian, Farnia and Suleiman (2009) studied the thanking expressions of Iranian EFL learners. They reported that Iranian and American respondents employed the same patterns of strategies in responding to the questionnaires. However, the findings of this study suggested that language proficiency did not affect EFL learners' use of strategies while expressing gratitudes in English.

Janani(1995), on the other hand, investigates the issue of levels of proficiency on gratitude expressions of Persian EFL learners. He claims that the differences which exist between the performances of students from different levels of proficiency is meaningfully significant.

Therefore, careful consideration of the controversial results of previous studies can lead us to the fact that a comprehensive study is needed for finding the reality about the ways in which gender and levels of proficiency may affect the Iranian EFL learners' thanking expressions.

\section{METHODOLOGY}

This study seeks to answer the following research questions:

Q1: Is there any significant difference between expressions of thanking used by Iranian EFL learners according to their level of proficiency?

Q2: Is there any significant difference between expressions of thanking of Iranian EFL learners according to their gender?

\subsection{Participants}

Sixty EFL learners, including 30 male and 30 female students were randomly selected from BA and MA students of the Najafabad University and students learning English in a language institutes located in Najafabad. The participants' age ranged from 18 to 26 and they were from different regions of Iran. Participants were selected from different genders to investigate the role of sex in the selection of thanking strategies.

Table 1

Summary of some specifications about participants

\begin{tabular}{ccc}
\hline & Male & Female \\
\hline Age (mean) & 21.85 & 20.2 \\
\hline Gender & 30 & 30 \\
\hline
\end{tabular}

\subsection{Instruments}

As to the purpose of the present study, the following types of materials were used for data collection:

\section{The Oxford Placement Test}

The Oxford Placement Test (Allan, 2004) is a valid and reliable test and a highly effective instrument in grouping students into appropriate levels. It can also be used as a quick measurement of students' general language proficiency. The test and its criteria for placement was used to appropriately place learners in relevant proficiency levels. 
Table 2

Frequency of the individuals accoding to their level of proficiency

\begin{tabular}{|c|c|c|c|c|}
\hline & Total & Advance & $\begin{array}{l}\text { Upper- } \\
\text { intermediate }\end{array}$ & Intermediate \\
\hline Frequency & 60 & 20 & 20 & 20 \\
\hline $\begin{array}{l}\text { Frequency } \\
\text { percentage }\end{array}$ & 100 & 33.3 & 33.3 & 33.3 \\
\hline
\end{tabular}

\section{The Discourse Completion Test (DCT)}

In this study the DCT from a previously conducted study by Pishghadam and Zarei (2011) was used for collecting the needed data. The test consists of 13 scenarios and the respondents were supposed to imagine themselves in each situation and respond accordingly based on their immediate reaction.

The DCT constituted two main parts. In the first part, the participants were asked to give some information about their age and sex. In the second part, the participants were to read the scenarios, and react to them via expressing gratitude.

\subsubsection{Rationale to Apply a Previously used Instrument}

Reviewing the literature of speech act research conducted in the Iranian context shows that the researchers use either standard or self-designed format of DCTs. Obviously the standard version of the DCT which have been designed and validated by the Iranian-speaking researchers are more suitable for eliciting data; therefore instead of designing a new DCT, the researcher applied a standard one to facilitate the process of data collection.

\subsection{Procedures}

As the initial stage, a proficiency test (Oxford Placement Test (OPT)) was administered to ascertain the level of proficiency of participants, then all the 60 participants of the study were asked to complete a DCT and after gathering the needed data the participants responses were coded in accordance with a coding scheme proposed by Cheng (2005), finally the utterances of male and female participants from different levels of proficiency were compared with each another. The thanking strategy consists of two major subcategories: (a) simple thanking, by using the word thank you or thank, and (b) elaborated thanking, including four sub-subcategories (i) by thanking and adding one intensifier, (ii) by thanking and adding two intensifiers (iii) thanking for (reason), by thanking and mentioning the reason, and (iv) thanking + intensifier + for (reason), by thanking and adding intensifier(s) and the reason. Coding and examples are provided for each subcategory as follows:

(a) Simple thanking, by using the word thank you or thanks

_//Ty// Thank you.

_/Ts// Thanks.

(b) elaborated thanking

(i) by thanking and adding one intensifier

_//TI// Thank you very much.

- //TI// Thanks a lot.

(ii) by thanking and adding two intensifiers

//TII// Thank you very much indeed.

(iii) by thanking and stating the reason (thanking + for + reason). The reason

is further categorized into three parts: favor (coded as $/ / \mathrm{Rf} / /$ ), imposition (coded as $/ / \mathrm{Ri} / /$ ), and positive feelings (coded as //Rp//)

_//TRf// Thank you for your consideration and your attention to all of the things that we brought forward. 
(iv) by thanking and adding both intensifier(s) and the reason (thanking +intensifier + for + reason). //TIRf// Thank you very much for showing us your home.

3.4. Data Analysis

After gathering the needed data via using a DCT, the responses of learners within each group of proficiency were coded according to the scheme proposed by Cheng, and then the thanking expressions of male and females within each group were compared and contrasted with one another.

\section{RESULTS}

The two hypotheses of the study mentioned below were tested, the results of which would be yielded in details.

1. There is no significant difference between the expressions of thanking used by Iranian EFL learners according to their level of proficiency.

2. There is no significant difference between expressions of thanking used by Iranian EFL learners according to their gender.

\subsection{Research Hypothesis 1}

There is no significant difference between the expressions of thanking used by Iranian EFL learners according to their level of proficiency.

In order to see whether this is the case or not, the participants were classified according to their level of proficiencies, then the thanking strategies which had been codified according to the Cheng coding scheme were compared with one another. The results revealed a significant difference between the participants with different levels of proficiency. Table 3 summarizes the frequency percentage of the strategies used by individuals in each level of proficiency.

Table 3

Frequency percentage of the strategies used by individuals with different levels of proficiency

\begin{tabular}{|ccc|c|c|}
\hline \multicolumn{2}{|c|}{ Level of knowledge } & Frequency & Percent \\
\hline intermediate & Valid & A-a & 13 & 65.0 \\
& & A-bi & 7 & 35.0 \\
& & Total & 20 & 100.0 \\
\hline upper intermediate & Valid & A-a & 4 & 20.0 \\
& & A-bi & 3 & 15.0 \\
& & A-bii & 13 & 65.0 \\
& Total & 20 & 100.0 \\
\hline \multirow{2}{*}{ advanced } & Valid & A-bi & 1 & 5.0 \\
& & A-bii & 7 & 35.0 \\
& A-biii & 12 & 60.0 \\
& Total & 20 & 100.0 \\
\hline
\end{tabular}

According to the above mentioned table advanced students tend to use the A-biii strategies more than the other types of the strategies while the upper- intermediates prefer the A-bii strategies.

The following table deals with the amount of the difference which exists between the individuals with different levels of proficiency. 


\section{Table 4}

Differences between the individuals according to their level of proficiency

\begin{tabular}{|c|c|c|c|c|c|}
\hline & $\begin{array}{c}\text { Sum of } \\
\text { Squares }\end{array}$ & df & Mean Square & F & Sig. \\
\hline Inter-group & 48.400 & 2 & 24.200 & 56.417 & .000 \\
Within group & 24.450 & 57 & .429 & & \\
total & 72.850 & 59 & & & \\
\hline
\end{tabular}

\subsection{Research Hypothesis 2}

There is no significant difference between expressions of thanking used by Iranian EFL learners according to their gender

Careful consideration of the results presented in the following tables can reveal the differences that exist between the male and female Persian speakers.

Table 5

Frequency percentage of the strategies according to the gender of individuals

\begin{tabular}{|cc|c|c|}
\hline & & Frequency & $\begin{array}{c}\text { Frequency } \\
\text { Percentage }\end{array}$ \\
\hline M & & 13 & 43.3 \\
& A-a & 4 & 13.3 \\
& A-bi & 11 & 36.7 \\
& A-bii & 2 & 6.7 \\
& A-biii & 30 & 100.0 \\
\hline F & Total & 4 & 13.3 \\
& A-a & 7 & 23.3 \\
& A-bi & 9 & 30.0 \\
& A-bii & 9 & 33.3 \\
& A-biii & 10 & 100.0 \\
\hline
\end{tabular}

As can be seen the male participants preferred the A-a strategies while the female ones used the A-bii and A-biii strategies with a higher degree of frequency. 


\section{Table 6}

Differences between the individuals according to their level of proficiency

\begin{tabular}{|c|c|c|c|c|c|}
\hline & $\begin{array}{c}\text { Sum of } \\
\text { Squares }\end{array}$ & df & Mean Square & F & Sig. \\
\hline Inter-group & 8.817 & 1 & 8.817 & 7.986 & .006 \\
Within group & 64.033 & 58 & 1.104 & & \\
Total & 72.850 & 59 & & & \\
\hline
\end{tabular}

The data presented in the above mentioned table displays the role of gender in applying different types of strategies for expressing gratitude toward others.

\section{DISCUSSION OF FINDINGS}

The first research question addressed the effects level of proficiency may have on selecting the strategies of gratitude. In response to this question, the first null hypothesis was formulated. Regarding the speech act of thanking the results of the present study revealed a significant effect of the level of knowledge on using different types of strategies.

Advanced participants of the study preferred the complicated type of strategies within but the upper-intermediate and intermediate individuals used the strategies that were a bit simpler according to the Cheng coding scheme.

The second research question focused on the difference between male and female EFL learners in employing thanking strategies. Findings showed that females try harder for expressing gratitude in order not to threaten the face of their addresses. Therefore, it was concluded that there was a difference between male and female respondents as far as employing the thanking strategies are concerned.

The findings with respect to the second hypothesis were in accordance with those of Pishghadam and Zarei (2011); within their article they state that females are more conservative than the male speakers. The reason Parvaresh and Eslami rasekh (2009) proposed for the conservative behavior of the female Persian speakers is related to the Islamic culture of Iran. They state that whenever the addressee is of the opposite sex, solidarity is usually overridden by considerations of deference. They relate the behavior of the Iranian females to the element of social power which is generally associated with males. Another reason for their finding is related to the psychological factors that may challenge the young women from each society. They assert that the young girls prefer the indirect ways of expressing imposition, just to make their speeches more ladylike.

In addition, with regard to the second hypothesis, the findings of this study run counter to previous research by Farahani \& Molkizadeh (2013), Koczogh's (2011), and Okamoto (2002). Farahani \& Molkizadeh (2013) showed that gender has no significant role in the process of strategy selection. Moreover, Koczogh's (2011) found no statistically significant gender difference in his data in the use of different types of strategies in terms of their frequency.

Likewise, the findings of the present study is in opposition to Okamoto's (2002, p.102) view that "gender cannot be isolated as an independent variable for determining language use, and other variables need to be considered as simultaneously relevant". Gender and politeness researchers should pay greater attention to intra-gender and inter-gender similarities in strategic discourse, as the data has revealed, there are many interesting patterns that, whilst traditionally ascribed to both male and female speech style politeness, are used differently by the two groups.

\section{CONCLUSIONS}

Based on the above-presented discussion some concluding remarks can be drawn. Most importantly, a positive correlation was found between being a female and degree of conservativeness. That is, female participants were more concerned about the face needs of their 
addresses. This study also found significant differences between the strategies that male and female respondents with different levels of proficiency selected to express gratitude to their addresses.

Thus, according to the results of the present study, although one cannot make big claims regarding the generalizability of the findings, it can be concluded that both gender and level of proficiency can strongly affect the process of strategy selection. The following conclusions were, eventually, drawn as the results of the present study:

1. Level of proficiency has a significant effect on using different strategies of gratitude.

2. Significant differences exist between the thanking strategies that male and female EFL learners mostly employ.

\section{References}

[1] Allan, D. (2004). Oxford Placement Test 2: Test Pack. Oxford University Press.

[2] Apte, M. L. (1974). "Thank you" and South Asian languages: a comparative sociolinguistic study. International Journal of the Sociology of Language, 1974(3), 67-90.

[3] Blum-Kulka, S., \& Olshtain, E. (1984). Requests and Apologies: A Cross-Cultural Study of Speech Act Realization Patterns(CCSARP). Applied linguistics, 5(3), 196-213.

[4] Bodman, J., \& Eisenstein, M. (1988). May God increase your bounty: The expression of gratitude in English by native and non-native speakers. Cross currents, 15(1), 1-21.

[5] Cheng, S. W. (2005). An exploratory cross-sectional study of interlanguage pragmatic development of expressions of gratitude by Chinese learners of English. A doctoral dissertation, University of Iowa.

[6] Cheng, S. W. (2010). A corpus-based approach to the study of speech act of thanking. Concentric: Studies in Linguistics, 36(2), 257-274.

[7] Cohen, A. (1996). Speech Acts. In S.L. McKay, \& N.H. Hornberger (Eds.), sociolinguistics and language teaching (pp. 383 - 420). Cambridge: Cambridge University Press.

[8] Coulmas, F. (1981). Poison to your Soul, Thanks and Apologies Contrastively Viewed, Coulmas, F.(ed.) Conversational Routine, Rasmus Rask Studies in Pragmatic Linguistics, vol. 2.

[9] Cutting, J. (2005). Pragmatics and discourse: A resource book for students. Routledge, London.

[10] Eisenstein, M., \& Bodman, J. W. (1986). 'I very appreciate': expressions of gratitude by native and non-native speakers of American English. Applied linguistics, 7(2), 167- 185.

[11] Eisenstein, M., \& Bodman, J. (1993). Expressing gratitude in American English. Interlanguage pragmatics, 6481.

[12] Farnia, M., \& Suleiman, R. (2009). An interlanguage pragmatic study of expressions of gratitude by Iranian EFL learners-A pilot study. Malaysian Journal of ELT Research, 5, $108-140$

[13] Hinkel, E. (1994). Native and nonnative speakers' pragmatic interpretations of English texts. Tesol Quarterly, 28(2), 353-376.

[14] Holmes, J. (1986). Compliments and compliment responses in New Zealand English. Anthropological linguistics, 485-508.

[15] Hymes, D. H. (1972). On communicative competence. In B. Pride \& J. Holmes (Eds.), Sociolinguistics (pp.269-293). Harmondsworth: Penguin.

[16] Janani, M. (1995). Pragmatic Failure of Iranian Language Learners in Expressing Gratitude (Doctoral dissertation, MA thesis. Tarbiat Modarres University. Tehran, Iran). 
[17] Johansen, S.H. (2008). A comparative study of gratitude expressions in Norwegian and English from an interlanguage pragmatic and second language acquisition research perspective. A doctoral dissertation,University of Oslo.

[18] Koczogh, H. V. (2011). Gender Differences in Disagreement Strategies Employed by Speakers of Hungarian. California Linguistic Notes, 36(2).

[19] Mey, J. L. (1993). Pragmatics: an introduction. Oxford: Blackwell.

[20] Miyake, K. (1994). Wabi'igaide tsukawareru wabi hyogen: Sono tayoukatno jittaito uchi, soto, yosono kankei ('Formulaic apologies in non-apologetic situations: A data analysis and its relation with the concept of uchi-soto-yoso'). Nihongo Kyouiku (Journal of Japanese Language Teaching), 82, 134-146.

[21] Nakai, M., \& Watanabe, Y. (2000). A study on expressions of gratitude in Japanese and American English. Journal of Pan-Pacific Association of Applied Linguistics, 4(1), 200-216.

[22] Nakata, T. (1989). Hatsuwa koui to shiteno chinsha to kansha: Nichi-ei hikaku (Apology and thanks as speech acts: Comparison between Japanese and English). Nihongo Kyouiku, 68, 191-203.

[23] Nakamura, K. (2005). Appreciation Strategies of German and Japanese Native Speakers and German Learners of Japanese. Proceedings of the 4th Annual JALT Pan-SIG Conference. May 14-15, 2005. Tokyo, Japan: Tokyo Keizai University

[24] Okamoto, S. (2002). Ideology and social meanings: rethinking the relationship between language, politeness, and gender. In Sara Benor et al. (Eds.) Gendered practices in language (pp. 91-113). Stanford, CA: CSLI Publications.

[25] Pishghadam, R., \& Zarei, S. (2011). Expressions of Gratitude: A Case of EFL Learners. Review of European Studies, 3(2).

[26] Pomerantz, A. (1978). Compliment responses: Notes on the co-operation of multiple constraints. Studies in the organization of conversational interaction, 7, 112.

[27] Van Ek, J. A. (1977). The threshold level for modern language learning in schools. Longman Publishing Group.

[28] Wardhaugh, R. (2002). An introduction to psycholinguistics (4th Ed.). Oxford: Blackwell Publishers Ltd.

[29] Wolfson, N., \& Manes, J. (1980). The compliment as a social strategy. Research on Language \& Social Interaction, 13(3), 391-410. 